\title{
Effect of Nd:YAG Laser Irradiation on Human Dental Enamel
}

\author{
By \\ Kunio HASHIGUCHI and Kenji HASHIMOTO \\ The Department of Oral Surgery, Hamamatsu University School of Medicine, \\ 3600 Handa-cho, Hamamatsu, Shizuoka, 431-31, Japan \\ - Received for Publication, May 10, 1990-
}

\begin{abstract}
Key words: Dental enamel, Pulsed Nd:YAG LASER, $\alpha-\mathrm{TCP}$
Summary: The crystallographic alterations of the hydroxyapatite under the laser irradiation were evaluated by the $x$-ray diffraction pattem analysis and scanning electron microscopic observation. Recrystallization may occur in fused and resolidified dental enamel by the pulsed Nd: YAG laser irradiation. Two different grades of energy densities such as 400 pulses and 800 pulses were given to the powdered enamel. The irradiation was performed at a peak power of $500 \mathrm{~W}$ with a pulse width of $10 \mathrm{msec}$; the average output of $10 \mathrm{~W}$, spot size of $3 \mathrm{~mm}$ and two pulses were given in every second. After the 800 pulses of Nd:YAG laser irradiation to the human dental enamel the $x$-ray diffraction pattern demonstrated both $\alpha$-tricalcium phosphate and hydroxyapatite peaks. With the lower level of energy at $\mathbf{4 0 0}$ pulses, no significant differences were seen in the diffraction patterns between lased and unlased enamel. In scanning electron microscopic findings, there were no significant changes between lased and unlased enamel. When the unlased and lased enamel were exposed to acid solution, unlased enamel showed a honeycomb pattern, while the lased enamel showed preferentially removed prism core material.
\end{abstract}

Recent progress in beam solid interaction and transient processes is remarkable. And interaction between dislocation and recombination induced by the laser irradiation has come to our interest. Crystal catalysis and structural changes of the hydroxyapatite may occur at the certain transition temperature under the laser irradiation. This method of laser light amplification with the stimulated emission of irradiation was firstly invented by Maiman (1960), and has been extensively applied in many scientific fields. In dentistry, Goldman (1964) made an attempt to replace the dental drill by the laser. Vahl et al. (1968) reported on structural changes in dental enamel due to laser irradiation; the dental structure exposed to the ruby laser was changed as a result of melting. Sognnaes and Stern (1965) found that the enamel surface of extracted teeth exposed to the ruby laser had changed to demineralized subsurface with more resistance than that of preexposure. Stern et al. (1972) described the effects of $\mathrm{CO}_{2}$ laser on the dental enamel by the examinations of microradiography and scanning of electron microscopy. Yamamoto et al. (1980) reported that the acid resistance was imparted to the enamel by irradiation with an acousto-optically Q-switched $\mathrm{Nd}: \mathrm{YAG}$ laser, normal-pulsed Nd:YAG laser and Pokels cell Qswitched Nd:YAG laser. These results suggested that the $\mathrm{Nd}$ :YAG laser irradiation could change the surface of enamel structure and an effective procedure for the prevention of dental caries. Vahl (1968) and Kantola (1973) analyzed by x-ray microanalysis and stated that the $\mathrm{x}$-ray diffraction pattern of the enamel after the $\mathrm{CO}_{2}$ laser or the ruby laser irradiation was altered with the production of tricalcium phosphate (TCP) instead of hydroxyapatite. Matsui (1984) investigated the diffraction pattern of the synthesized hydroxyapatite in both exposed and unexposed to $\mathrm{CO}_{2}$ laser irradiation, and found that lased apatite was consistent with small amount of $\alpha$-TCP (Matherw, M. et al. 1977) and $\beta$-TCP (Dickens, B. et al. 1974).

The aim of this study is to clarify the crystallographic changes and superficial alteration in lased enamel by means of $x$-ray diffraction method and scanning electron microscope. This report attempts to determine the superficial alteration in the hydroxyapatite which may increase the resistance to dental caries.

\section{Materials and Methods}

Materials and devices: In each experiment, the teeth enamel were used as experimental and control samples. All teeth were freshly extracted from noncarious human teeth. Calculus adherent to the tooth was easily detached by well directed instrumentation. The enamel 
surface was polished using a rubber polishing cup with a paste of fine pumice in water. In the first step of experiment before laser irradiation, powdered sample of about $10-20 \mu$ in diameter was grinded by a diamond point. These materials were divided into two groups to be examined under the unlased and lased situation. The analysis of diffraction pattern was performed in the synthesized hydroxyapatite, unlased and lased (400 pulses and 800 pulses) enamel powder.

The device used in this study was NEC Co. SL-124CW. This machine has a wave length of $1.06 \mu$. The laser was focused to give a $3 \mathrm{~mm}$ of spot size guided by the optical fiber. The sizes of irradiation were peak power of $500 \mathrm{~W}$, pulse width of $10 \mathrm{msec}$, average output of $10 \mathrm{~W}$ and two pulses every second. A individual pulse had $5 \mathrm{~J} / \mathrm{cm}^{2}$ of energy. The visible guideline was the red $\mathrm{HeNe}$ light. The hydroxyapatite synthesized by reaction of $\mathrm{Ca}(\mathrm{OH})_{2}$ and $\mathrm{H}_{3} \mathrm{PO}_{4}$ aqueous solution in $37^{\circ} \mathrm{C}$ of stirring bath were heated up to approximately $1200^{\circ} \mathrm{C}$. Under the above condition, the powdered enamel in a thin layer sandwiched between the glass plates were irradiated.

X-ray analysis: Samples of the powdered enamel obtained from a teeth were exposed to the pulsed $\mathrm{Nd}$ :YAG laser under different conditions. The low angle experiments were performed on $\mathrm{CuK}_{\alpha}$ radiation monochrometer using Rigaku diffractometer. Nifiltered $\mathrm{CuK}_{\alpha}$ radiation was used at the voltage level of $40 \mathrm{KV}$, and the emission current of $100 \mathrm{~mA}$ and the count range of $1000 \mathrm{cps}$ were set. The Rigaku goniometer was employed to obtain the automatic recording.

SEM: Sample tooth was equally cut into six pieces. After the enamel sample were exposed to the pulsed $\mathrm{Nd}$ :YAG laser at 400 pulses and 800 pulses, three pieces of tooth were treated with $0.1 \mathrm{H} \mathrm{HCl}$ for $40 \mathrm{sec}$. The teeth were placed in $3 \%$ glutaraldehyde buffer at $\mathrm{pH}$ 7.4 in $0.1 \mathrm{M}$ sodium cacodylate and post fixed in $1 \%$ osmic acid for 1 hour using the same buffer. All samples were critical point dried in a Polaron 3000 critical point dryer. The resulting dried surfaces were coated with gold with thickness of approximately $30 \mu$ in a Polaron sputler coater. Scanning electron microscope was used with the resultant images recorded on film.

\section{Results}

The X-ray diffraction patterns were essentially identical in synthesized hydroxyapatite, unlased and lased dental enamels. The diffraction patterns of the synthesized apatite (Fig. 1) were compared with those of unlased and lased enamel samples, and no significant differences were evaluated. The analysis of the diffraction patterns revealed that the pattern of synthesized hydroxyapatite were clearly sharper than those of unlased or lased enamel with 400 pulses (Fig.
1-3). In the diffraction pattern of unlased enamel powder (Fig. 2), there were several peaks of hydroxyapatite in the region of $2 \theta=21.7^{\circ}, 22.8^{\circ}, 25.8^{\circ}$, $28.0^{\circ}, 28.8^{\circ}$, and peak groups were in the $2 \theta=$ $31^{\circ}-34^{\circ}$. The diffraction pattern of the enamel samples exposed to intense laser irradiation was shown in Fig. 3 and 4. The X-ray diffraction analysis showed no differences in the patterns between the lased (400 pulses) and unlased enamel. This diffraction pattern seen in Fig. 3 was similar to that of unlased enamel shown in Fig. 2. This finding suggested that hydroxyapatite of enamel were not changed after the pulsed Nd:YAG laser irradiation with lower energy of 400 pulses. The peaks of the diffraction patterns in each sample had similarity, however, there was a small peak in the position of $2 \theta=30.8^{\circ}, 31.3^{\circ}$ and $34.1^{\circ}$ perceptible only in case of lased enamel with 800 pulses (Fig. 4). This was because of conclusive proof of the laser effect on changes occurred in the crystal structure of the enamel. The diffraction pattern illustrated in Fig. 1-4 were obtained from the synthesized hydroxyapatite, unlased enamel and lased enamel (JCPD 9-432,348) respectively, and the angle region of $20^{\circ}<2 \theta<50^{\circ}$ were shown in each pattern. The peaks of $2 \theta=30.8^{\circ}$ and $31.3^{\circ}$ (arrows) in lased enamel with 800 pulses may fit exactly the small peaks of $\alpha$-TCP. The amplitude of the peak was small but distinct beside the strongest peak of $2 \theta=34.1^{\circ}$ (arrows) indicating small amount of $\alpha$-TCP. The structural changes of the hydroxyapatite was caused by laser irradiation of 800 pulses, and $\alpha$-TCP might be decomposed in this situation. No morphological differences between unlased and lased tooth was detected by SEM (Fig. 5). While the tooth was placed in $0.1 \mathrm{~N} \mathrm{HCI}$ in $40 \mathrm{sec}$., two patterns of enamel surface etching were seen. There was a generalized roughing of the enamel surface with hollows at the prism centers and intact peripheral regions. The average diameters of the hollows were about $3 \mu$. These morphological characters were seen as the most common pattern of enamel surface etching (Fig. 6). Prism peripheries appeared to be removed or heavily damaged. The prism cores were left from the original enamel surface (Fig. 7, 8). In views of SEM, lased enamel surface (400 and 800 pulses) had separate cores of material (Fig. 7, 8). The gaps inbetween multiple cores were melt and spread out. This etching pattern was apparently different from the honey comb pattern which was the characters in unlased enamel.

\section{Discussion}

The structural changes produced by various laser in dental enamel has been studied by means of microradiography, SEM and x-ray diffraction method. The reresistance of the enamel surface may obtained 
by laser irradiation. Our SEM studies described that pulsed Nd:YAG laser irradiation produced decomposition of fusing and recrystallization in the enamel. The portion of the lased tooth which viewed with SEM are shown in Figure 5.

The determination of decomposition on tooth surface produced by the laser irradiation is technically difficult. We grinded the human dental enamel powder in order to attempt to study the superficial alteration. But there was no significant changes in diffraction patterns with relatively low energy irradiation. The Xray diffraction method is useful in the determination of the decomposition product, and we used it to ensure their identification. Recrystallization with laser effects could be checked by the peaks of diffraction pattern in lased enamel with 800 pulses. The peaks represented at $2 \theta=30.8^{\circ}, 31.3^{\circ}$ and $34.1^{\circ}$ fit the distinct peaks of $\alpha$-TCP, and those were absent in lased enamel with 400 pulses. The enamel consist of $\mathrm{Ca}$ deficient apatite (Posner, A.S. 1962), such as dislocation, vacancies, replacement of $\mathrm{Ca}$ by proton. These lattice imperfections was weak points to laser beams so that dental enamel destruction occured in these regions. Heating the enamel powder by laser irradiation caused a little dehydration and formation of $\alpha$-TCP. The dental enamel is observed at the hexagonal cell, and $\alpha$-TCP crystallized belongs to the monolinic space group of $\mathrm{P} 2$ /a. When examined in the SEM, enamel surface exposed to the laser was not different from the unlased enamel (Fig. 5). The lased and unlased enamel was put in $0.1 \mathrm{~N} \mathrm{HCI}$ for $40 \mathrm{sec}$. Two patterns of enamel surface etching were seen in Fig. 6-8, and those patterns were different in characters between unlased and lased enamel. The unlased surface shows a body of enamel prism and double wall structure. The pattern was different on etching enamel after the pulsed Nd:YAG laser irradiation, and subsurface enamel appeared to have melted crystals. The initial surface reaction after the exposure to $\mathrm{HCl}$ was characterized by a direct dissolution of the outer surface. (Silverstone, L.M. et al. 1975) With increasing time, crystalline enamel precipitated at the surface concomitantly with a reduction in the removal of mineral from the inner enamel. The X-ray diffraction pattern did not indicate any changes in the hydroxyapatite which may inhibit enamel demineralization by the laser irradiation. (Aoki, H. et al. 1975) The unknown substance, however not clearly determined in our experiments, absorbed on the enamel surface in saliva could exist, and it could possibly detectable by means of the scanning tunneling microscopy.

\section{Conclusion}

The crystallographic alteration produced by the pulsed Nd:YAG laser was studied by X-ray diffraction and SEM methods. The different peaks at $2 \theta=30.8^{\circ}$, $31.3^{\circ}$ and $34.1^{\circ}$ were observed in lased enamel with 800 pulses. However, our study was not satisfactory proved as positive to the fact that the Nd:YAG laser is effective for the prevention of dental caries.

\section{Acknowledgement}

We wish to express our gratitude to Professor Hajime Yamamoto, Department of Oral Pathology, and Professor Shigetoshi Shioda, First Department of Oral Surgery, Faculty of Dentistry, Tokyo Medical and Dental University, and Professor Kenshiro Takamori, Department of Oral Bacteriology, Faculty of Dentistry, Showa University, for their valuable advice.

\section{References}

1) Aoki, H., Akao, M., Innan, Y. and Yamada, T.: Sobility properties of TCP. Jpn. J. Dent. Mater., 3B: 67-68, 1984 (in Japanese).

2) Dickens, B., Schroeder, L. W. and Brown, W. E.: Crystallographic studies of the role of $\mathrm{Mg}$ as a stabilizing impurity in $\beta-\mathrm{Ca}_{3}\left(\mathrm{PO}_{4}\right)_{2}: 1$. The crystal pure $\beta-\mathrm{Ca}_{3}\left(\mathrm{PO}_{4}\right)_{2}$. J. Solid State Chemistry, 10: 232-248, 1974.

3) Goldman, L., Horby, P., Meyer, R. and Goldman, B.: Impact of the laser on dental caries. Nature, 203: 417, 1964.

4) Kantola, S., Laine, E. and Tarna, T.: Laser induced effect on tooth structure; $x$-ray diffraction study of dental enamel exposed to a $\mathrm{CO}_{2}$ laser. Acta. Odont. Scand., 31: 369-379, 1973.

5) Maiman, T.H.: Stimulated optical radiation in ruby. Nature, 187: 439-494, 1960.

6) Matherw, M., Schroeder, L. W., Dickens, B. and Brown, W. E.: the crystal structure of $\alpha-\mathrm{Ca}_{3}\left(\mathrm{PO}_{4}\right)_{2}$. Acta Cryst., B33: 1325-1333, 1977

7) Matsui, K.: Decomposition product of hydroxyapatite irradiated by $\mathrm{CO}_{2}$ laser and its tissue reaction with bone. Jpn. J. Dent. Mater., 7: 102-108, 1984 (in Japanese)

8) Posner, A. S., Stutman, J. M. and Lippincott, E. R.: Hydrogen-bonding in calcium deficient hydroxyapatite. Nature, 184: 486-487, 1960 .

9) Silverstone, L. M., Saxton, C. A., Pogon, I. L. and Fejerskov, O.: Variation in the pattern of acid etching of human dental enamel examined by scanning electron microscopy. Caries Res., 9: 373-387, 1975 .

10) Stern, R. H., Vahl, J. and Sognnaes, R. F.: Ultrastructural observation of pulsed carbon dioxide laser effect. J. Dent. Res., 51: $455-460,1972$.

11) Sognnaes, R. F. and Stern, R. F.: Laser effect on resistance of human dental enamel to demineralization in vitro. J. South. Calif. Assoc., 33: 328-329, 1965.

12) Vahl, J.: Electron microscopic and x-ray crystallographic investigation of teeth exposed to laser rays. Caries Res., 2 $10-18,1968$.

13) Yamamoto, H. and Sato, K.: Prevention of dental daries by Nd:YAG laser irradiation. J. Dent. Res., 59: 2171-2177. 1980 
274 K. Hashiguchi and K. Hashimoto

Plate I
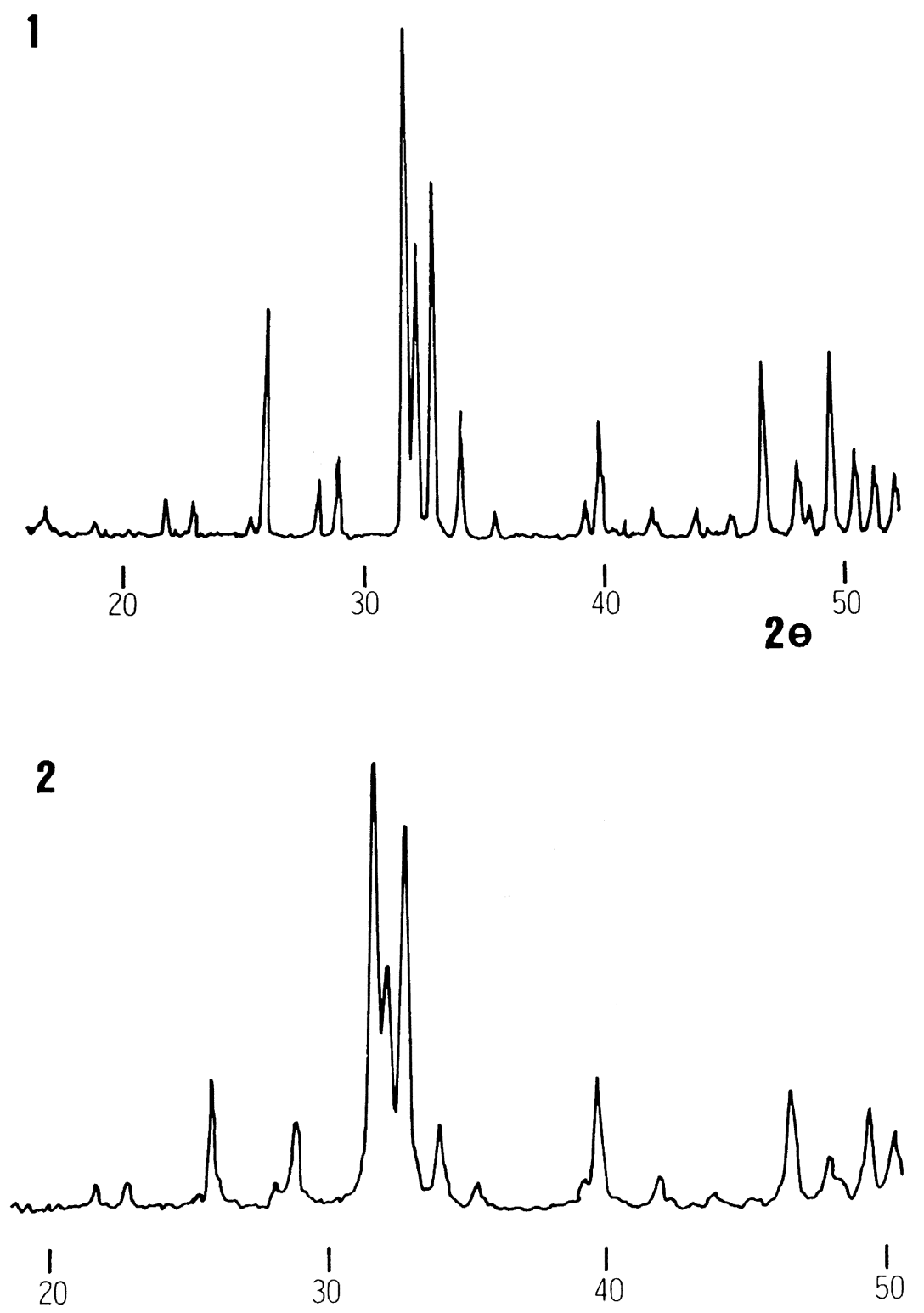

\section{Explanation of Figures}

Plate I

Fig. 1. X-ray diffraction pattern of synthesized hydroxyapatite heated at $1200^{\circ} \mathrm{C}$.

Fig. 2. Unlased enamel. 
Plate II
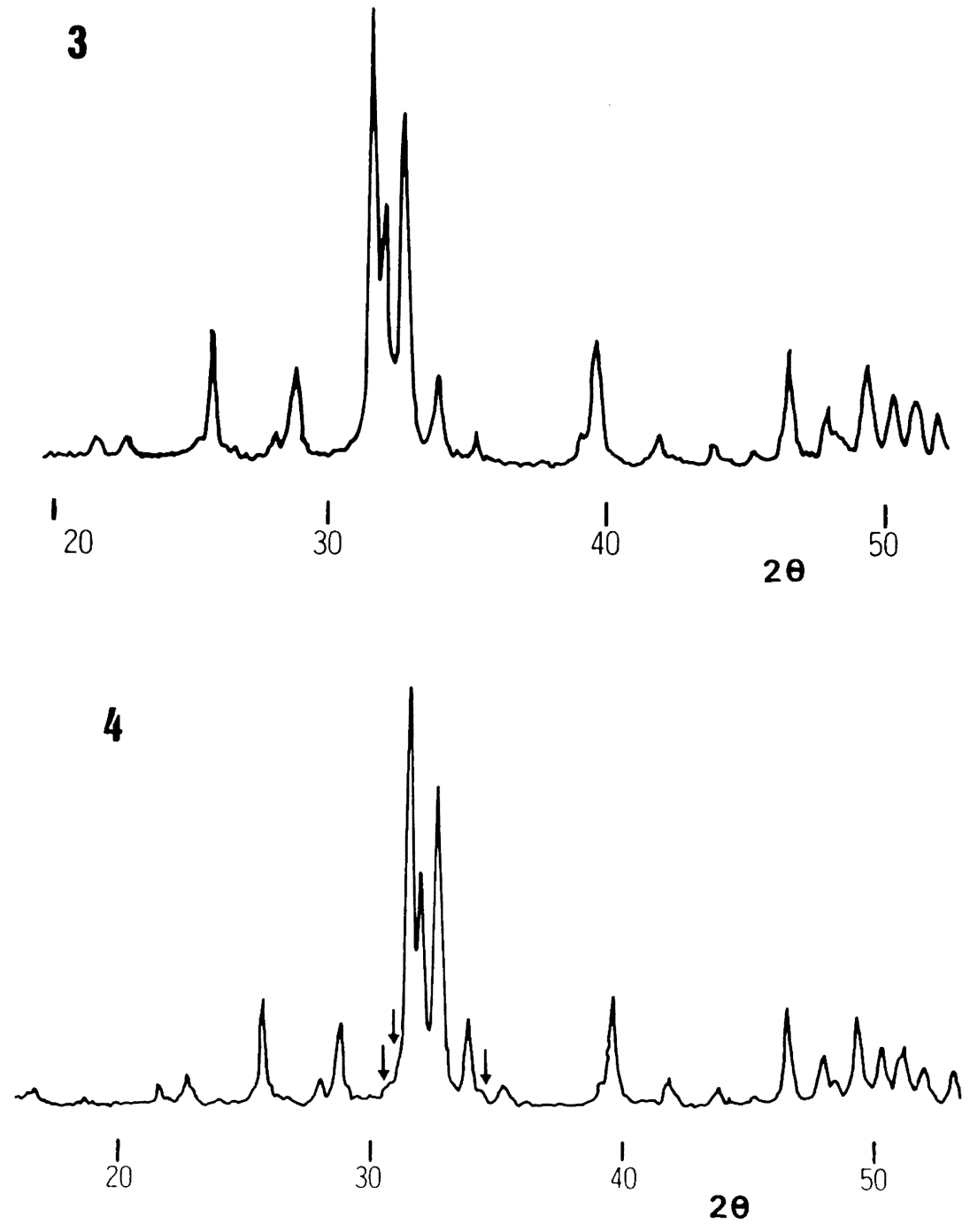

Plate II

Fig. 3. Lased enamel (400 pulses).

Fig. 4. Lased enamel (800 pulses). Arrow Indicates $\alpha$-TCP. 
Plate III

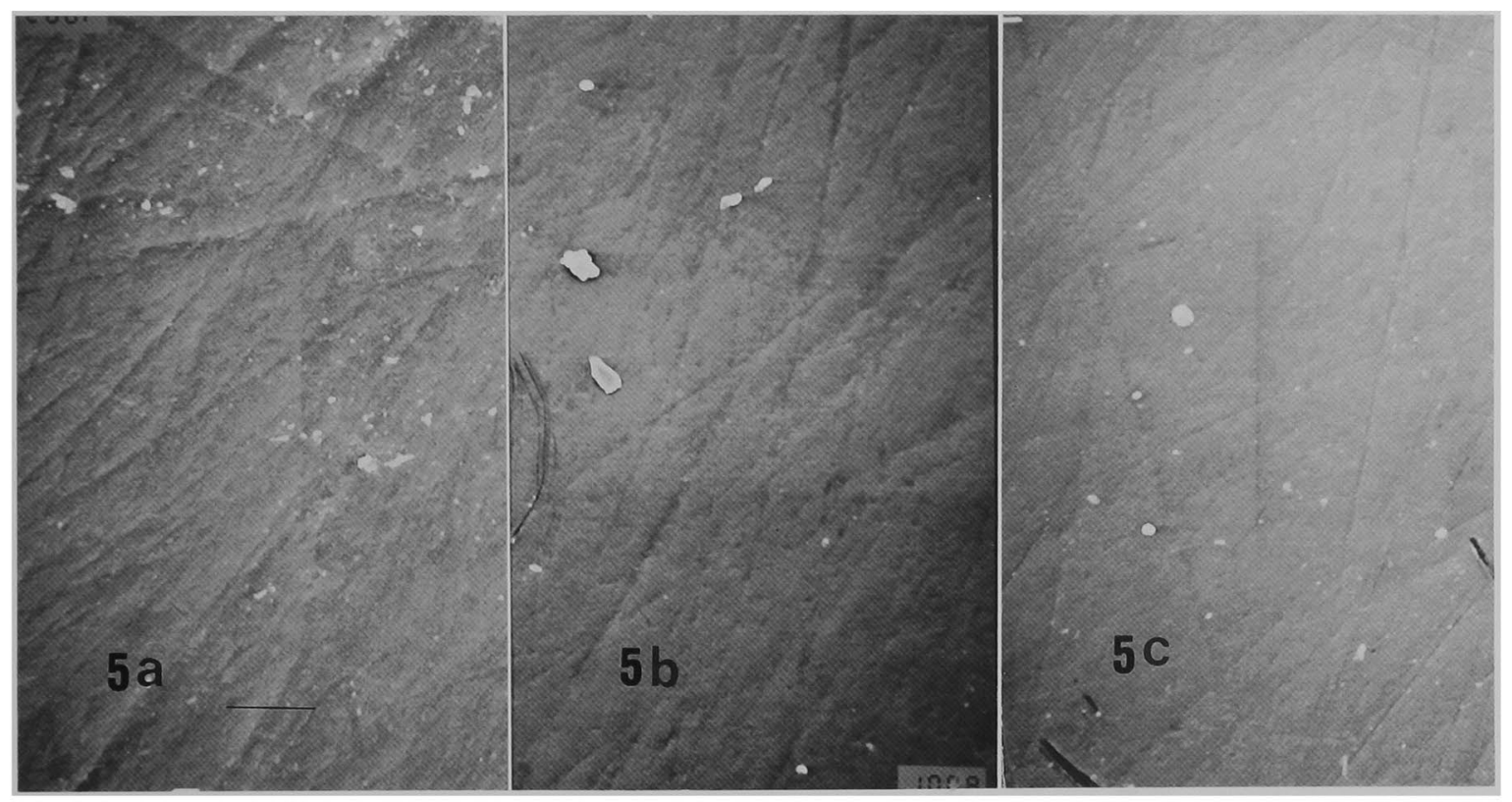

\section{Plate III}

Fig. 5. a: SEM view of unlased enamel surface. b: Lased enamel surface ( 400 pulses). c: Lased enamel surface $(800$ pulses $)(\times 1000)$. There are no significant changes between unlased and lased enamel. $\mathrm{Bar}=10 \mu$ 


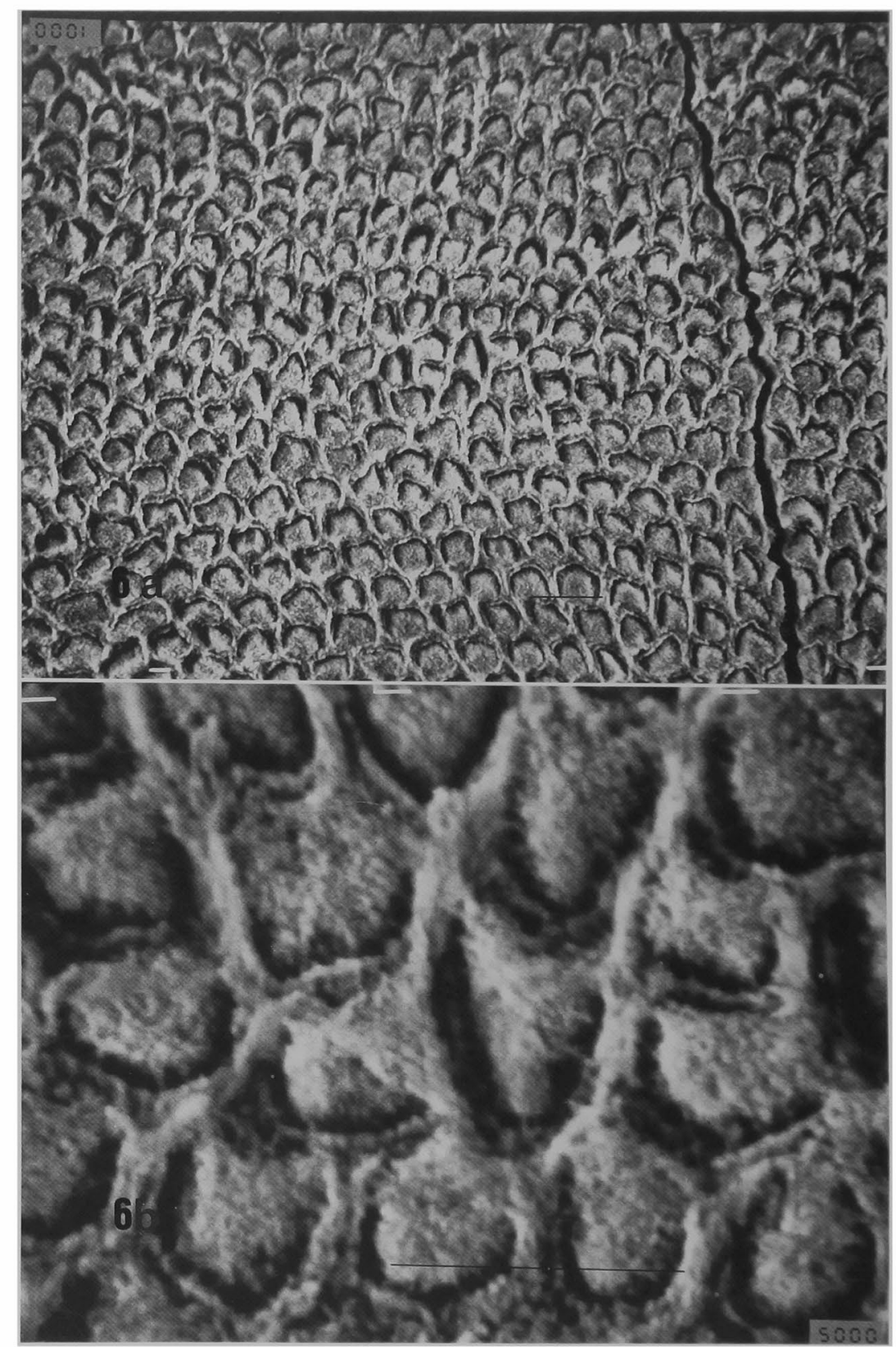

\section{Plate IV}

Fig. 6. a: SEM view of unlased enamel surface that was exposed to $0.1 \mathrm{~N} \mathrm{HCI}$ for $40 \mathrm{sec} .(\times 1000)$ This type of damage was most commonly seen. $\mathrm{Bar}=10 \mu$

b: Unlased enamel shown at high magnification $(\times 5000)$ Bar $=10 \mu$ 
Plate V
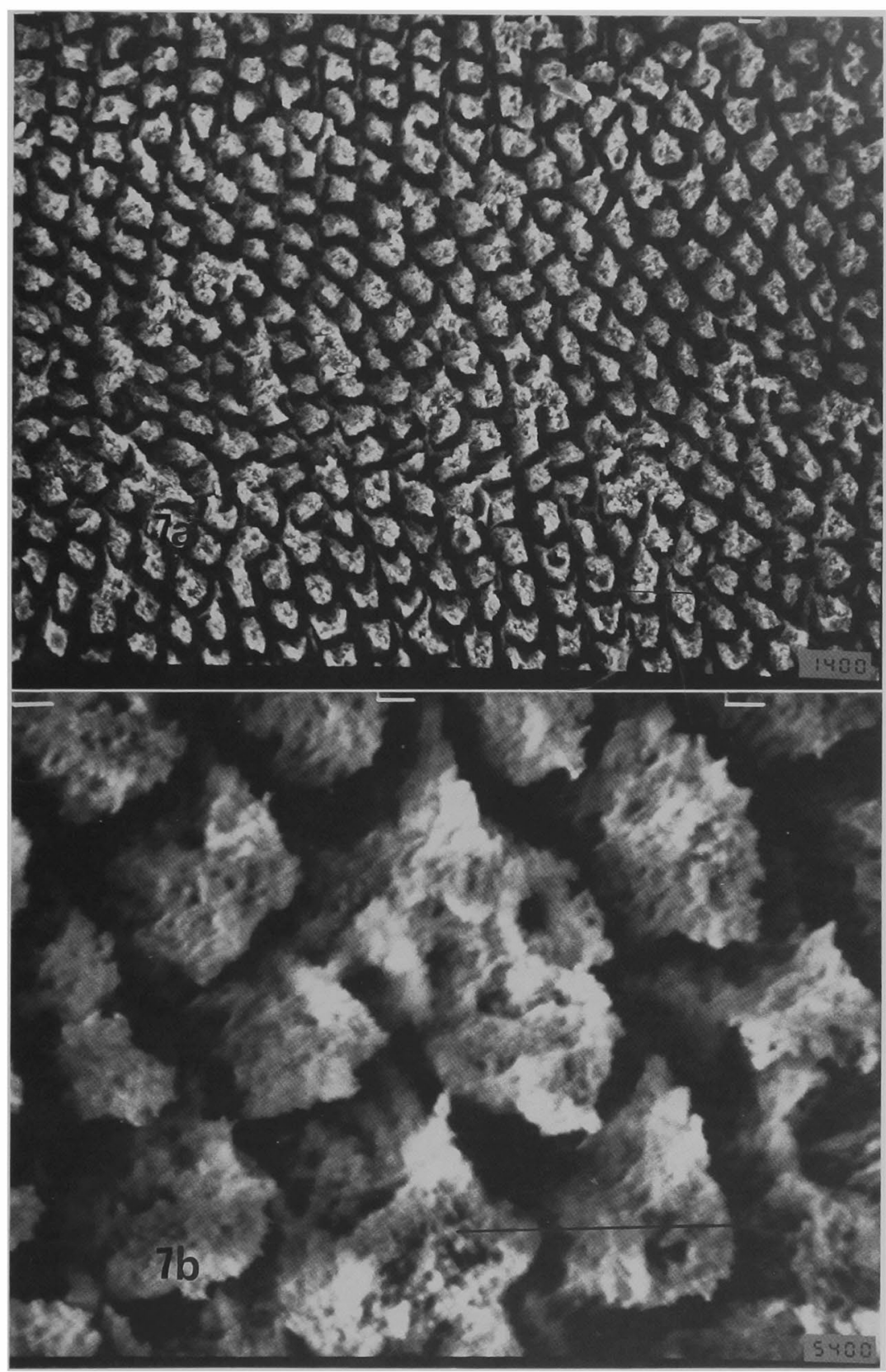

\section{Plate V}

Fig. 7. a: Lased enamel surface ( 400 pulses) exposed to $0.1 \mathrm{~N} \mathrm{HCI}$ for $40 \mathrm{sec} .(\times 1000)$ Separate prism cores are seen, the gaps separating them corresponding to prism peripheries. $\mathrm{Bar}=10 \mu$

$\mathrm{b}$ : The surface seen in the previous figure at high magnification. $(\times 5000) \mathrm{Bar}=10 \mu$ 
Plate VI
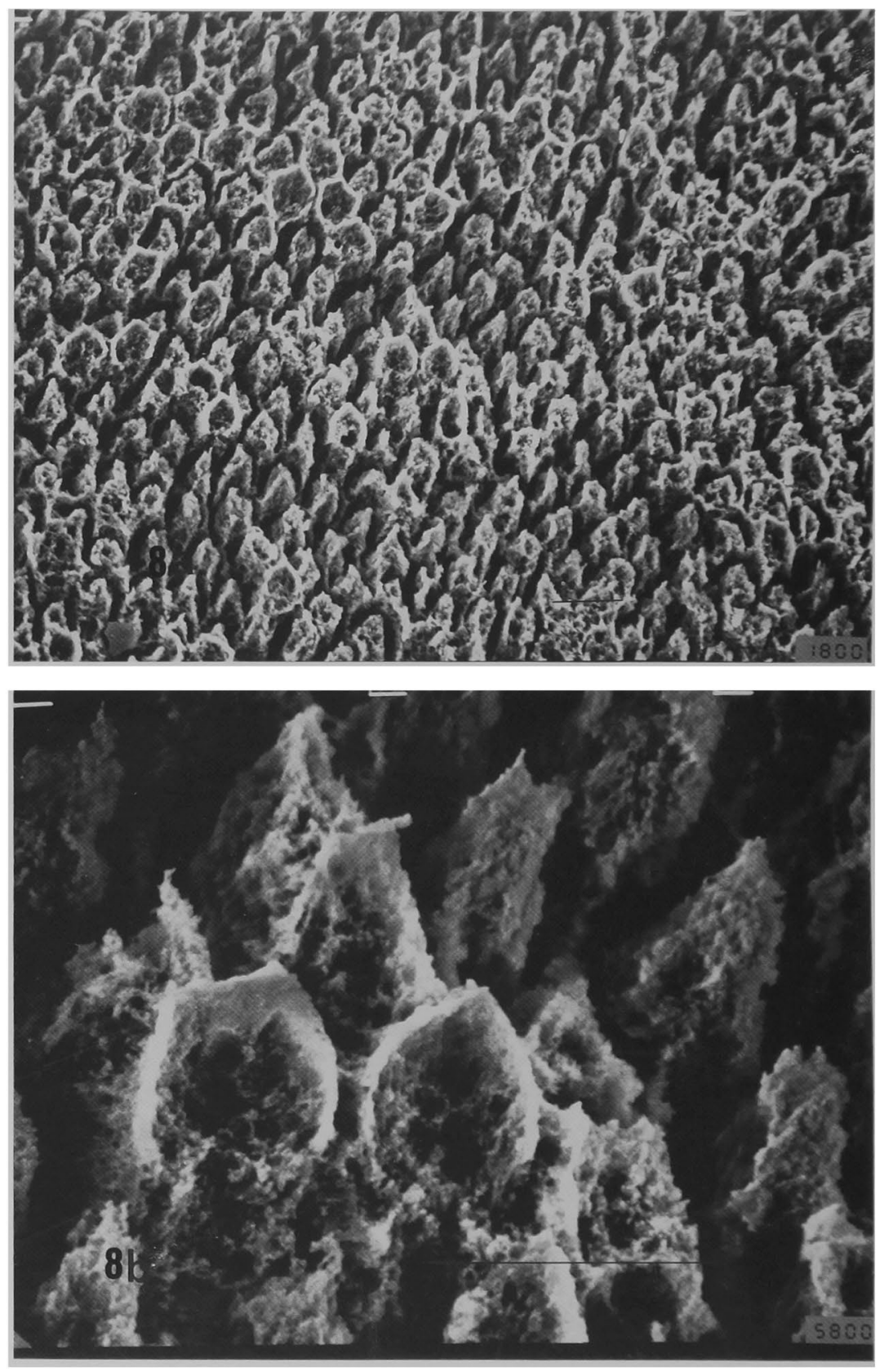

\section{Plate VI}

Fig. 8. a: Lased enamel surface $(800$ pulses $)$ exposed to $0.1 \mathrm{~N} \mathrm{HCI}$ for $40 \mathrm{sec}$. $(\times 1000)$ The peripheral regions of prisms are removed preferentially. Remaining prism cores are relatively undamaged. $\mathrm{Bar}=10 \mu$ b: At high magnification. $(\times 5000) \mathrm{Bar}=10 \mu$ 